\title{
Aplicação de uma sequência didática lúdica e interdisciplinar no desempenho escolar de alunos com dificuldades $e$ distúrbios de aprendizagem
}

\author{
Application of a ludic and interdisciplinary teaching sequence in the school \\ performance of students with difficulties and learning disorders \\ Leticia Gonçalves Borin Moro \\ Janaína Pereira Pretto Carlesso
}

\begin{abstract}
Resumo: A presente pesquisa, teve como objetivo investigar se a aplicação de sequências didáticas interdisciplinares de natureza lúdica auxiliam na aprendizagem de crianças com dificuldades e distúrbios de aprendizagem. O estudo é de caráter qualitativo, tendo como técnica de pesquisa a pesquisa-ação, foi realizada em uma turma de $2^{\circ}$ ano do ensino fundamental de uma escola Municipal de Santa Maria, RS. $\mathrm{Na}$ turma estudada foram aplicadas duas vezes por semana, durante o ano de 2019, sequências didáticas interdisciplinares de caráter lúdico. No estudo, analisou-se se as práticas pedagógicas interdisciplinares auxiliam no desempenho escolar dos alunos com dificuldades e distúrbios de aprendizagem, para isso foram realizadas três avaliações de desempenho dos alunos, formuladas pela pesquisadora professora regente da amostra estudada, contendo questões sobre alfabetização, embasadas teoricamente nas hipóteses de aquisição da escrita de Ferreiro e Teberosky. A pesquisa realizada aponta que alunos com distúrbios de aprendizagem necessitam não só de técnicas e metodologias de ensino dinâmicas, para isso, é fundamental que os professores estejam conscientes do seu papel, estando atentos aos sinais que aparecem no contexto da sala de aula e no desempenho/comportamento do aluno. No entanto, o educador poderá realizar os encaminhamentos necessários para intervir a tempo e contribuir no processo de ensino e aprendizagem.
\end{abstract}

Palavras-chave: Dificuldades. Distúrbios de aprendizagem. Ludicidade. Ensino. Interdisciplinaridade.

Abstract: This research aimed to investigate whether the application of interdisciplinary didactic sequences of a playful nature helps in the learning of children with learning difficulties and disorders. The study is of a qualitative character, having research-action research as a research technique, it was carried out in a class of 2nd year of elementary school at a Municipal school in Santa Maria, RS. In the studied group, interdisciplinary didactic sequences of a playful nature were applied twice during the year 2019. In the study, it was analyzed whether interdisciplinary pedagogical practices help the school performance of students with learning difficulties and disorders, for that purpose three evaluations of students' performance were carried out, formulated by the researcher professor conducting the studied sample, containing questions about literacy, based on theoretically in the hypotheses of acquisition of the writing of Ferreiro and Teberosky. The research carried out shows that students with learning disorders need not only dynamic teaching techniques and methodologies, for that, it is essential that teachers are aware of their role, being attentive to the signs that appear in the classroom context and in 
performance / student behavior. However, the educator will be able to make the necessary steps to intervene in time and contribute to the teaching and learning process.

Keywords: Difficulties. Learning disorders. Playfulness. Teaching. Interdisciplinarity.

\section{Introdução}

A interdisciplinaridade, cada vez mais, é discutida e estudada no campo da educação como uma alternativa para auxiliar o processo de ensino e aprendizagem e torná-lo mais atraente aos alunos. Ela visa superar a visão fragmentada de produção do conhecimento, articulando as disciplinas, buscando estabelecer uma visão de conjunto, com objetivos interligados. A interdisciplinaridade, de acordo com Fazenda (2011, p. 34), consiste "num trabalho em comum tendo em vista a interação das disciplinas científicas, de seus conceitos e diretrizes, de suas metodologias, de seus procedimentos, de seus dados e da organização de seu ensino".

O modo de trabalhar com a perspectiva interdisciplinar exige dos envolvidos uma visão ampla sobre a articulação e o envolvimento entre as disciplinas, pois os conhecimentos devem estar ligados entre si. No entanto essa prática não visa à eliminação das disciplinas, ela busca criar práticas de ensino que estabeleçam uma dinamicidade entre as disciplinas, ou seja, que elas se entrelacem, buscando, assim, resolver os problemas da realidade que fazem parte. "A real interdisciplinaridade é antes uma questão de atitude, supõe uma postura única diante dos fatos a serem analisados, mas não significa que pretenda impor-se, desprezando suas particularidades" (FAZENDA, 2011, p. 59).

Por isso, tratar sobre o assunto e colocá-lo em prática requer rigor, estudos e muita cautela, pois,

Não é uma questão de deslocamento, mas de vinculação, de atitude, de um olhar cruzado entre o que se sabe e o que se pode aprender com outros sujeitos e outros saberes; em sua gênese, podemos explicitar que a interdisciplinaridade busca uma nova forma de compreensão a respeito do conhecimento e sua produção. (FÁVERO; TONIETO, CONSALTÉR, 2018)

Mesmo sendo muito comum falar sobre esse tema, é notório que seu entendimento ainda não está claro dentro das instituições de ensino, pois, para 
o ensino se tornar realmente interdisciplinar, é necessário bem mais que um professor realizar alguma atividade relacionando as disciplinas. Primeiramente, é necessário muito estudo e debate entre os envolvimentos no sistema educacional e, só após o real entendimento do tema, proporcionar atividades com envolvimento e engajamento de todos.

[...] A interdisciplinaridade será possível pela participação progressiva num trabalho de equipe que vivencie esses atributos e vá consolidando essa atitude. É necessário, portanto, além de uma interação entre teoria e prática, que se estabeleça um treino constante no trabalho interdisciplinar, pois, interdisciplinaridade não se ensina, nem se aprende, apenas vive-se, exerce- se. Interdisciplinaridade exige um engajamento pessoal de cada um. Todo indivíduo engajado nesse processo será o aprendiz, mas, na medida em que familiarizar-se com as técnicas e quesitos básicos, o criador de novas estruturas, novos conteúdos, novos métodos, será motor de transformação (FAZENDA, 2011, p. 94).

Para que essa prática se torne possível, é necessário o envolvimento de todos no sistema de ensino e ainda a reflexão constante sobre a prática. Só assim surgirão práticas que sejam capazes de auxiliar as crianças a tornar 0 processo de ensino e aprendizagem mais significativo.

A Base Nacional Comum Corricular (BNCC), é um documento que define um conjunto progressivo e orgânico de aprendizagens essenciais que devem ser desenvolvidos nos alunos ao longo da educação básica e ela afirma:

Nos dois primeiros anos do Ensino Fundamental, a ação pedagógica deve ter como foco a alfabetização, a fim de garantir amplas oportunidades para que os alunos se apropriem do sistema de escrita alfabética de modo articulado ao desenvolvimento de outras habilidades de leitura e de escrita e ao seu envolvimento em práticas diversificadas de letramentos. (BRASIL, 1996, P. 59)

Verifica-se assim que é fundamental articular os vários campos do conhecimento no processo de alfabetização, como aponta o Parecer CNE/CEB $n^{\circ} 11 / 201029$, "os conteúdos dos diversos componentes curriculares [...], ao descortinarem às crianças o conhecimento do mundo por meio de novos olhares, Ihes oferecem oportunidades de exercitar a leitura e a escrita de um modo mais significativo" (BRASIL, 2010). 
Pensando nisso, muitas das aulas interdisciplinares estão ocorrendo por meio da ludicidade. Luckesi (2004) afirma que a atividade lúdica é aquela que propicia à pessoa que a vive uma sensação de liberdade, um estado de plenitude e de entrega total para essa vivência. Ela é uma das maneiras mais eficazes para envolver os educandos nas atividades, pois as brincadeiras estão na essência da infância, é muito mais divertido aprender brincando. "O que a ludicidade traz de novo é o fato de que o ser humano, quando age ludicamente, vivencia uma experiência plena. [...] Não há divisão" (LUCKESI, 2006, p. 2).

A ludicidade pode ser utilizada como forma de sondar,
introduzir ou reforçar os conteúdos, fundamentados nos
interesses que podem levar o aluno a sentir satisfação em
descobrir um caminho interessante no aprendizado. Assim, o
lúdico é uma ponte para auxiliar na melhoria dos resultados
que os professores querem alcançar (BRASIL, 2007).

A ludicidade para se tornar realidade na prática requer atitude do educador, pois envolve muitas demandas, estudos e técnicas adequadas.

A ludicidade na educação requer uma atitude pedagógica por
parte do professor, o que gera a necessidade de envolvimento
com a literatura da área, da definição de objetos, organização
de espaços, da seleção e da escolha de brinquedos
adequados e o olhar constante nos interesses e das
necessidades dos educandos. (PEREIRA, LIMA, PEREIRA,
2020, p.4)

Tornar o ensino lúdico e interdisciplinar, no sentido real da palavra, dá trabalho e demanda tempo do educador, visto que é necessário, além de planejamento e pesquisa de acordo com as necessidades dos alunos, preparar jogos e atividades de maneira lúdica, ou seja, construí-los e, para isso, o professor vai precisar disponibilizar seu horário de descanso nos fins de semana e custear com seu próprio recurso financeiro. Por isso, muitas vezes, o professor apenas utiliza o que a escola disponibiliza e nem sempre esses jogos estão de acordo com a necessidade dos alunos.

Outro fator que deve ser levado em consideração é que, na atividade lúdica, o professor também precisa estar atento, observar as crianças brincando e trabalhando, procurar observar os seus comportamentos, suas reações, o que mais lhes chama a atenção, suas dúvidas, suas necessidades. Além 
disso, deve brincar diretamente com a criança, de modo que ela se solte e o professor entenda o que aquele momento representa para a criança e o que a criança necessita para a próxima atividade desenvolvida.

O papel do professor durante os jogos deve ser o de provocar e desafiar a participação coletiva na busca de encaminhamentos e resolução dos problemas, pois é através do jogo que podemos despertar e incentivar a criança para o espírito de companheirismo de cooperação gradativamente, ela vai assumindo e compreendendo sua posição como um membro de um grupo social (SANTOS, 1998, p. 52).

Muitas vezes, o que dificulta o uso da ludicidade como efetivamente uma metodologia é o fato que ela desacomoda o modo tradicional do andamento da aula. A aula com ludicidade e interdisciplinaridade é com movimento e muito mais barulho que a habitual, o aluno necessita entender as "regras do jogo" e aprender a respeitá- las, assim como respeitar seus colegas. Além disso, também é fundamental que as famílias estejam cientes dos métodos utilizados pelos professores, pois, na maioria dos casos, se não teve atividade no caderno, as famílias pensam que as crianças não fizeram nada naquele dia escolar.

Ao abordar uma intervenção educativa por meio da ludicidade e da interdisciplinaridade, é importante trabalhar com estratégias didáticas com envolvimento de todos no contexto escolar, professores, gestores e famílias. Ao contrário serão apenas atividades divertidas e provavelmente sem alcançar o objetivo maior, que é promover uma aprendizagem mais significativa de uma maneira mais envolvente e cativante. A partir de tais considerações iniciais, o objetivo neste estudo é analisar os reflexos da aplicação de três sequências didáticas interdisciplinares e de caráter lúdico no desempenho escolar de alunos com dificuldades e distúrbios de aprendizagem de uma turma de alunos do $2^{\circ}$ ano do ensino fundamental.

\section{Metodologia}

A presente pesquisa caracteriza-se por ser uma pesquisa-ação de cunho qualitativo. Pesquisa-ação permite que o pesquisador conheça, analise e interfira dentro de uma problemática social. Por meio desse tipo de pesquisa, o 
docente poderá refletir criticamente sobre suas ações de modo a contribuir, cada vez mais, para a aprendizagem da turma.

[...] um tipo de pesquisa social com base empírica que é concebida e realizada em estreita associação com uma ação ou com a resolução de um problema coletivo e no qual os pesquisadores e os participantes representativos da situação ou do problema estão envolvidos do modo operativo ou participativo (THIOLLENT, 2011, p. 14).

Assim, com a pesquisa-ação, busca-se intervir na prática, aprimorandoa, contribuindo para sanar dificuldades. Como instrumento de coleta de dados, foram utilizadas avaliações construídas pela pesquisadora, professora regente da turma aplicadas ao término do $1^{\circ}$ trimestre, do $2^{\circ}$ trimestre e do $3^{\circ}$ trimestre no ano de 2019.

A primeira avaliação, aplicada ao final do primeiro trimestre, era composta por duas atividades. A primeira era um ditado com 10 palavras e a segunda avaliação era escrever espontaneamente o nome das imagens, ambas tinham oobjetivo verificar o nível de escrita de cada criança, utilizando como método os níveis de escrita de acordo com Ferreiro e Teberosky (1991). A segunda avaliação foi aplicada ao final do segundo trimestre, era composta por três atividades. Na primeira, o educando deveria escrever o nome das figuras, na segunda, completar o nome das figuras com sílabas e, na terceira, resolver cálculos de adição e subtração. A primeira e a segunda atividades tinham a finalidade de verificar em qual nível de escrita se encontrava cada criança e o progresso que obtiveram em relação ao primeiro trimestre, bem como a percepção e aprendizagem em relação a cálculos simples de adição e subtração.

A terceira avaliação, realizada no final do terceiro trimestre, ou seja, no final do ano letivo, era constituída de cinco atividades. A primeira atividade foi um ditado com seis palavras; a segunda atividade era composta por um ditado de cinco frases; na terceira, os alunos deveriam escrever uma frase para cada imagem; a quarta atividade era constituída de cálculos matemáticos de adição e subtração; na quinta atividade, os alunos deveriam completar os números com antecessor e sucessor. Todas as atividades tinham como objetivo verificar o 
nível de escrita em que se encontrava cada aluno e refletir sobre os avanços que obtiveram em relação ao primeiro e segundo trimestres.

A amostra estudada foi composta por uma turma de 20 alunos com idades entre sete e oito anos, que frequentam o $2^{\circ}$ ano do ensino fundamental de uma escola da rede municipal de ensino de Santa Maria, RS. Os critérios de inclusão para composição da amostra do estudo foram: alunos (as) com dificuldades e distúrbios de aprendizagem sem intervenções de profissionais especializados. Também foram elaborados critérios de exclusão, tais como: alunos (as) com dificuldades e distúrbios de aprendizagem com intervenções e acompanhamentos de profissionais fora da escola. A partir de critérios apontados a amostra de estudos foi composta por 8 alunos.

\section{Procedimentos da Pesquisa}

Para analisar os reflexos da aplicação das sequências didáticas interdisciplinares com caráter lúdico no desempenho escolar de alunos com dificuldades/distúrbios de aprendizagem na amostra estudada, a pesquisadora elaborou três sequências didáticas interdisciplinares com caráter lúdico, para aplicação no contexto da sala de aula em cada trimestre do ano de 2019.

A ludicidade e a interdisciplinaridade envolveu e permeou todas as disciplinas e campos do conhecimento, seguindo os objetivos de aprendizagens e avanços almejados na aprendizagem da referida turma. Por exemplo, dentro de um jogo de sílabas e montagens de palavras também era utilizado sequências, cores, número de sílabas, etc... envolvendo diversas áreas e necessidades de aprendizagens.

Para essas intervenções, foram utilizados diferentes jogos sobre alfabetização e estudos em locais não formais duas vezes por semana durante dois semestres letivos. Com o emprego dessas estratégias em sala de aula, pretendeu-se verificar o quanto as atividades propostas na sequência didática interdisciplinar com caráter lúdico contribuiu para aprendizagem dos alunos com dificuldades e distúrbios de aprendizagem participantes do estudo.

Para a avaliação dos reflexos no desempenho dos alunos durante a aplicação da sequência didática, a pesquisadora, professora regente da turma 
de alunos estudada, elaborou questões sobre alfabetização, embasadas teoricamente nas hipóteses de aquisição da escrita de Ferreiro e Teberosky (1991). A avaliação foi realizada pela professora em três momentos: ao término do $1^{\circ}$ trimestre, do $2^{\circ}$ trimestre e do $3^{\circ}$ trimestre durante o ano letivo.

Para realizar o acompanhamento do desempenho das crianças ao longo do ano, foram consideradas as hipóteses de aquisição da escrita de Ferreiro e Teberosky (1991). Os cinco níveis de escrita, segundo a psicogênese da língua escrita, são os seguintes: nível pré-silábico, silábico, silábico-alfabético, alfabético e ortográfico. Essas hipóteses representam as etapas trilhadas pela criança no seu processo de aprendizagem da escrita como sujeito que constrói seu conhecimento por meio de tentativas próprias. A seguir, no quadro 1, são apresentados os níveis de escrita e suas características.

Quadro 1 - Hipóteses de aquisição da escrita de Ferreiro e Teberosky (1991) e suas características.

\begin{tabular}{|c|c|}
\hline $\begin{array}{c}\text { Hipóteses de aquisição da } \\
\text { Escrita }\end{array}$ & Características \\
\hline Hipótese pré-silábica & $\begin{array}{c}\text { É a primeira fase da criança, na qual ela } \\
\text { reproduz traços da escrita com os quais teve } \\
\text { contato. }\end{array}$ \\
$\begin{array}{c}\text { Essas escritas são grafismos separados entre } \\
\text { si e tanto podem ser números como letras. } \\
\text { A criança também faz relação entre o } \\
\text { tamanho da palavra e o tamanho do objeto. }\end{array}$ \\
\hline Hipótese silábica & $\begin{array}{c}\text { Nessa etapa, observa-se a tentativa da } \\
\text { criança de dar um valor sonoro a cada uma } \\
\text { das letras que compõem uma escrita, ou seja, } \\
\text { cada letra corresponde a uma } \\
\text { sílaba. }\end{array}$ \\
\hline Hipótese silábico-alfabética & $\begin{array}{c}\text { Nessa hipótese de escrita, a criança começa a } \\
\text { abandonar a hipótese silábica e descobre a } \\
\text { necessidade de fazer uma análise que vá } \\
\text { além da sílaba. Há o conflito entre a hipótese } \\
\text { silábica e a exigência da quantidade mínima } \\
\text { de grafemas, além do conflito entre as formas } \\
\text { gráficas que o meio lhe propõe e a leitura } \\
\text { dessas formas em termos silábicos. A } \\
\text { hipótese silábica entra em contradição com o } \\
\text { valor sonoro atribuído às letras. Há uma } \\
\text { manifestação alternante do valor silábico ou } \\
\text { fonético para as diferentes letras. }\end{array}$ \\
\hline Hipótese alfabética & $\begin{array}{l}\text { Este é o nível no qual a criança já demonstra } \\
\text { ter compreendido que cada um dos caracteres } \\
\text { da escrita corresponde a valores sonoros } \\
\text { menores que a sílaba, realizando uma análise } \\
\text { sonora dos fonemas que vai utilizar ao } \\
\text { escrever as palavras. A partir desse momento, } \\
\text { a criança enfrentará alguns problemas típicos } \\
\text { de ortografia. }\end{array}$ \\
\hline
\end{tabular}




\begin{tabular}{|c|c|}
\hline Ortográfico & $\begin{array}{c}\text { Este é um nível em que se permanece em } \\
\text { contínua construção, em que se adquire e } \\
\text { domina as irregularidades da língua no } \\
\text { decorrer da vida. }\end{array}$ \\
\hline
\end{tabular}

Fonte: elaborado pela autora

\section{Resultados e discussões}

Nesta seção, apresenta-se a análise da aplicação das três sequências didáticas interdisciplinares de caráter lúdico aplicada a uma turma de alunos com dificuldades e distúrbios de aprendizagem durante o ano letivo de 2019.

Para obter os resultados, foram aplicadas avaliações na turma ao final do $1^{\circ}$ trimestre, do $2^{\circ}$ trimestre e do $3^{\circ}$ trimestre. A análise foi embasada nos níveis de aquisição da escrita de Ferreiro e Teberosky (1991). No quadro 2, é possível verificar a avaliação dos alunos da amostra estudada.

\begin{tabular}{|c|c|c|c|c|}
\hline GÊNERO & IDADE & $\begin{array}{r}1^{\circ} \text { AVALIAÇÄO } \\
\text { NIVEL }\end{array}$ & $\begin{array}{c}2^{\circ} \text { AVALIAÇÄO } \\
\text { NÍVEL }\end{array}$ & $3^{\circ}$ AVALIAÇÃO NÍVEL \\
\hline $\begin{array}{l}\text { Masculino } \\
\text { (B) }\end{array}$ & $\begin{array}{l}9 \text { anos e } 4 \\
\text { meses }\end{array}$ & $\begin{array}{l}\text { - Nível pré - } \\
\text { silábico }\end{array}$ & -silábico & - Silábico \\
\hline $\begin{array}{l}\text { Masculino } \\
\text { (C) }\end{array}$ & $\begin{array}{l}7 \text { anos e oito } \\
\text { meses }\end{array}$ & $\begin{array}{l}\text { - Nível pré - } \\
\text { silábico }\end{array}$ & $\begin{array}{l}\text {-pré- } \\
\text { silábico }\end{array}$ & $\begin{array}{c}\text { Pré- } \\
\text { silábico }\end{array}$ \\
\hline $\begin{array}{l}\text { Masculino } \\
\text { (D) }\end{array}$ & $\begin{array}{l}7 \text { anos e } 7 \\
\text { meses }\end{array}$ & $\begin{array}{l}\text {-Nível pré - } \\
\text { silábico }\end{array}$ & $\begin{array}{l}\text {-pré- } \\
\text { silábico }\end{array}$ & silábico \\
\hline $\begin{array}{l}\text { Feminino } \\
(\mathrm{F})\end{array}$ & $\begin{array}{l}7 \text { anose } 7 \\
\text { meses }\end{array}$ & $\begin{array}{l}\text {-Nível pré - } \\
\text { silábico }\end{array}$ & $\begin{array}{l}\text {-pré- } \\
\text { silábico }\end{array}$ & silábico \\
\hline $\begin{array}{c}\text { Masculino } \\
(\mathrm{G})\end{array}$ & $\begin{array}{l}7 \text { anos e } 10 \\
\text { meses }\end{array}$ & $\begin{array}{l}\text { - Nível pré - } \\
\text { silábico }\end{array}$ & -Silábico & $\begin{array}{l}\text { Silábico- } \\
\text { alfabetico }\end{array}$ \\
\hline $\begin{array}{l}\text { Masculino } \\
\text { (I) }\end{array}$ & $\begin{array}{l}8 \text { anos e um } \\
\text { mês }\end{array}$ & $\begin{array}{l}\text {-Nível pré - } \\
\text { silábico }\end{array}$ & -Silábico & Transferido \\
\hline $\begin{array}{c}\text { Masculino } \\
(\mathrm{J})\end{array}$ & $\begin{array}{l}7 \text { anos e } 5 \\
\text { meses }\end{array}$ & $\begin{array}{l}\text {-Nível pré - } \\
\text { silábico }\end{array}$ & -Silábico & Silábico \\
\hline $\begin{array}{c}\text { Masculino } \\
(\mathrm{K})\end{array}$ & $\begin{array}{l}7 \text { anos e } 5 \\
\text { meses }\end{array}$ & $\begin{array}{l}\text {-Nível pré - } \\
\text { silábico }\end{array}$ & $\begin{array}{l}\text { silábico- } \\
\text { alfabético }\end{array}$ & $\begin{array}{l}\text {-silábico - } \\
\text { alfabetico }\end{array}$ \\
\hline
\end{tabular}

Fonte: elaborado pela autora

No quadro 2, observa-se que houve avanços na aprendizagem da maioria dos alunos participantes da pesquisa. Esse avanço não se constituiu apenas em mudança de níveis, mas, sobretudo, de segurança para realizar as avaliações. É importante ressaltar que há diversos itens que conduzem à dificuldade de aprendizagem

1. [...] ordem motivacional que dizem respeito ao envolvimento cognitivo/afetivo com a aprendizagem, principalmente de natureza escolar. Muitas crianças 
com um potencial de aprendizagem favorável podem apresentar baixo desempenho acadêmico pelo fato de não verem razão para investir naquilo que a escola e/ou a família apresentam como importante. São crianças cuja motivação não está orientada para o sucesso acadêmico.

2. [...] dificuldades pontuais que revelam dúvidas específicas e não um transtorno de aprendizagem. [...] erros ortográficos específicos os quais podem ser superados assim que o conhecimento necessário seja a ela oferecido.

3. [...] Transtornos emocionais primários (ansiedade, depressão, fobias e psicoses) trazem desequilíbrio no plano relacional quanto acadêmico.

4. Transtornos Globais do desenvolvimento (TGD) afetam aspectos cognitivos, sociais/relacionais, comunicativos e motores, como deficiências mentais, autismo, de alterações de natureza sindrômica e de déficits neurológicos variados tendem, frequentemente, a comprometer a aprendizagem.

5. [...] crianças que não aprendem por apresentarem dificuldades ou mesmo falta de interesse. Também nos deparamos com outras cujo problema reside, fundamentalmente, na falta de oportunidades para aprender e não em suas capacidades para tanto.

6. [...] a forte influência que a própria escola exerce sobre aprendizagem na medida em que pode criar situações favoráveis ou desfavoráveis para tanto. As propostas pedagógicas podem ser atraentes ou não para os alunos, podem ser motivadoras ou até mesmo afastarem o interesse da criança (ZORZI, 2004).

Assim, muitos desses fatores podem ser superados com ações e práticas pedagógicas de caráter lúdico e dinâmicas levando em consideração que o educando é ser em movimento.

A primeira avaliação, segundo observações da pesquisadora referente ao comportamento dos alunos, foi marcada por manifestações emocionais, como choro, nervosismo e sentimento de incapacidade, na maioria das crianças. Antes de iniciar a avaliação, a pesquisadora, professora da turma, explicou que a atividade era apenas para testar o conhecimento de cada um, que era para fazer com tranquilidade, escrever do "jeitinho deles", mas, mesmo assim, a dificuldade e a insegurança que sentiam fez com que o nervosismo 
tomasse conta da turma, impossibilitando até de pensar, pois alguns apenas colocaram algumas letras soltas, dizendo que não "sabiam nada".

Para a realização da avaliação número 2 , a pesquisadora, professora da turma, utilizou praticamente a mesma fala, lembrando que não havia necessidade de ficarem nervosos, vistos que estão acostumados a realizar atividades na sala de aula, e ressaltou que são crianças inteligentes e capazes para realizá-las. Assim, surpreendendo até a professora/pesquisadora, as crianças realizaram as atividades com atenção e concentração, demonstrando avanço emocional e intelectual.

Na realização da atividade 3, não foi diferente, a professora explicou novamente como seria a realização da atividade, e os alunos realizaram a avaliação com calma e concentração, comprovando que, durante o ano, evoluíram muito emocionalmente, inclusive alguns relataram que adoravam fazer "esse tipo de atividade".

Sendo assim, ressalta-se que é fundamental considerar as emoções dos educandos nas operações mentais no processo de aprendizagem. Porém nem sempre essa questão é abordada como deveria, pois alguns professores acreditam que sala de aula é lugar apenas de estudar, de adquirir conhecimento e que as emoções são um assunto paralelo. Já outros consideram os fatores emocionais e afetivos como algo inerente ao indivíduo e, como tal, fazem parte do processo de aprendizagem.

Nessa perspectiva, Mayer e Salovey (1997) destacam que: A) a emoção torna o pensamento mais inteligente; B) a inteligência cognitiva auxilia $O$ indivíduo a pensar as suas emoções e as dos outros; C) a ausência dessa relação binomial torna o indivíduo emocional e socialmente incapaz.

Dessa forma, acredita-se que o modo com que a professora pesquisadora regente da turma orientou as crianças desde a primeira avaliação, buscando compreender o medo e a insegurança das crianças, contribuiu para que elas adquirissem segurança durante o processo, o que as motivou para realizar as avaliações posteriores. 
Analisando o desenvolvimento da turma ao longo do ano, analisou-se, em primeiro lugar, o avanço ou não de nível da primeira para a segunda avaliação, o que é objetivo principal no presente estudo.

No quadro 2, verificou-se que dos 8 alunos, cinco deles conseguiram avançar de nível do primeiro para o segundo trimestre. Entre os avanços, a grande maioria dos alunos avançou do nível pré-silábico para o silábico. Essa mudança significa um grande avanço na aprendizagem, pois denota que as crianças compreenderam a relação entre representação escrita das palavras e as propriedades sonoras das letras, representando por meio de uma letra para cada sílaba. A partir da evolução do nível pré-silábico para o silábico, as etapas de compreensão do sistema de leitura e escrita tendem à progressiva evolução.

A mudança qualitativa consiste em que: a) se supera a etapa de uma correspondência global entre forma escrita e a expressão oral (recorte silábico do nome); mas, além disso, b) pela primeira vez a criança trabalha claramente com a hipótese de que a escrita representa partes sonoras da fala (FERREIRO; TEBEROSKY, 1991, p. 193).

Assim, gradativamente, a criança vai compreendendo que as letras representam os sons e, partir daí, tendem a evoluir constantemente.

No quadro 2, também é possível identificar que três crianças ( $C, D$ e $F$ ) não avançaram de nível, mesmo demonstrando muito interesse e sendo assíduos nas aulas. Esses alunos demonstraram diversos tipos de dificuldade, inclusive os alunos C e D apresentaram dificuldades até em reconhecer cores, o que mostra que necessitam de encaminhamento para o atendimento especializado.

Os demais alunos que avançaram do nível pré-silábico para o nível silábico estão em progressivo desenvolvimento. Já outras crianças demonstram progresso em menor velocidade, mas o importante é que há evolução, que ocorre aprendizagem e que esta seja encarada com tranquilidade, sendo respeitadas as individualidades e o tempo de cada criança.

Quanto à evolução ou não da aprendizagem dos alunos da segunda para a terceira avaliação, pode-se verificar, no quadro 2, que cinco alunos se mantiveram no mesmo nível e uma criança foi transferida da escola por necessidade dos pais. 
Ressalta-se, de maneira importante, que, dos alunos que se mantiveram no mesmo nível de aprendizagem, apenas um aluno (C) não evoluiu em nenhum trimestre. Devido a isso e à não presença nas consultas do PRAEM, a educadora especial buscou ajudá-lo. Para isso, realizou alguns testes da área com esse aluno, detectando necessidade de ajuda especializada, pois ele apresenta sinais indicativos marcantes de distúrbio de aprendizagem e, por isso, necessitava do auxílio técnico de profissionais especializados. Assim, a educadora especial que atua na escola pesquisada, se prontificou a ajudá-lo com atendimento no contra turno escolar, porém a família do aluno disse que não teria como levá-lo. Acerca disso, cabe ressaltar que

É dever da família, da comunidade, da sociedade em geral e do Poder Público assegurar com absoluta prioridade, a efetivação dos direitos referentes à saúde, à alimentação, à educação, ao esporte, ao lazer, à profissionalização, à cultura, à liberdade e a convivência familiar e comunitária (BRASIL, 1990).

Os alunos $\mathrm{A}, \mathrm{B}, \mathrm{J}$ e $\mathrm{K}$ tiveram progresso de nível de aprendizagem na primeira avaliação e não obtiveram da segunda para terceira avaliação. Isso se justifica por diversos fatores, mas, entre os principais, destacam-se a bagagem de problemas pessoais enfrentados pelas crianças, relatados em conversas informais com a professora, o não comparecimento às consultas com a psicopedagoga do PRAEM, a falta de apoio familiar nos estudos, entre muitos outros. Esses aspectos se caracterizam por serem fatores extrínsecos da dificuldade de aprendizagem.

As dificuldades de aprendizagem abrangem vários fatores, uma vez que envolvem a complexidade do ser humano. Acredita-se que podem ser decorrentes de um problema fisiológico, um estresse grande vivido pela criança, como, por exemplo, problemas familiares envolvendo a perda de algum parente, problemas com alcoolismo ou drogas, separação dos pais, doenças, falta de alimentação, falta de material e estímulos, baixa autoestima (OSTI, 2012, p. 47).

Verifica-se, no contexto escolar, que, cada vez mais, as famílias, em suas diversas constituições, estão deixando a educação de seus filhos, tanto a formal como a não formal, sob responsabilidade unicamente da escola. Isso acontece pela necessidade de aumento da carga horária trabalhada, 
imaturidade da família ou por diversos outros fatores que causam prejuízos educativos e emocionais muito grandes nas crianças, já que elas necessitam de atenção e carinho de sua família para um desenvolvimento saudável.

Essa erosão do apoio familiar não se expressa só na falta de tempo para ajudar as crianças nos trabalhos escolares ou para acompanhar sua trajetória escolar. Num sentido mais geral e mais profundo, produziu-se uma nova dissolução entre família, pela qual as crianças chegam à escola com um núcleo básico de desenvolvimento da personalidade caracterizado seja pela debilidade dos quadros de referência, seja por quadros de referência que diferem dos que a escola supõe e para os quais se preparou (TEDESCO, 2002, p. 36).

Portanto, refletindo sobre os resultados da aplicação das sequências didáticas interdisciplinares e de caráter lúdico em três momentos, pôde-se verificar que a aplicação de tal instrumento em sala de aula proporcionou benefícios a toda turma, mas principalmente aos alunos com dificuldades de aprendizagem participantes da amostra deste estudo, pois trouxe muito além da aprendizagem, elas tornaram as aulas mais alegres, dinâmicas, aumentou a frequência escolar, os alunos relatavam a curiosidade que sentiam para saber qual seria a "brincadeira" que teriam naquele dia. Também foi possível verificar que a autoestima das crianças melhorou muito, pois as atividades proporcionavam que cada uma delas tivesse seu lugar, dando espaço para que elas próprias tomassem decisões e se ajudassem, valorizando o que cada uma tivesse de melhor.

As atividades lúdicas são ferramentas importantes não só para o desenvolvimento cognitivo da criança, como também em seu desenvolvimento social e afetivo, potencializando a capacidade de aprender ao socializar com o outro, haja vista que são sujeitos em contínua formação. Vygotsky traz aos nossos anseios ainda que é brincando bastante que a criança vai aprendendo a ser um adulto consciente, capaz de participar e engajar-se na vida de sua comunidade (VYGOTSKY, 1989, p. 82-83).

Além disso, também se constatou que a criança (D) ainda não está com maturidade suficiente para que o processo de alfabetização ocorra efetivamente, pois ainda se encontra egocêntrica e imatura tendo dificuldade de esperar sua vez, de compartilhar instrumentos, de concentra-se etc. 
Segundo Piaget (1994, p. 81), "o egocentrismo infantil é então, em sua essência, uma indiferenciação entre o eu e o meio social"; e em seu estágio de egocentrismo, a criança manifesta "falta de consciência do ego" (Piaget, 2005, p. 141), ou seja, a criança só percebe sua existência e seu ponto de vista, acreditando que tudo é seu, não percebendo a necessidade e a existência das outras crianças, caracterizando-se como uma centralização do pensamento em si mesma.

Para Piaget (1975), o processo da aprendizagem da escrita ocorre com a evolução do cognitivo, que acontece de dentro para fora, do indivíduo, de acordo com a maturidade que ele se encontra. Por isso, ainda há outros processos internos para ocorrer, e, só após, as crianças conseguirão entender o processo de leitura e escrita.

\section{Considerações finais}

O ser humano passa por constantes evoluções, o que resulta na construção de uma série de processos que se interligam. Assim, o desenvolvimento cognitivo está em constante evolução, se construindo e reconstruindo, permitindo que a aprendizagem se dê ao longo de toda a vida. Cabe ressaltar que a aprendizagem depende de diversos fatores internos e externos ao indivíduo. Por isso, é fundamental que os profissionais da educação sejam sensíveis e busquem estratégias que auxiliem no processo de ensino e aprendizagem de alunos com dificuldades e distúrbios de aprendizagem.

Sendo assim, considera-se que a pesquisa em questão, com a aplicação das sequências didáticas interdisciplinares e de caráter lúdico, teve seus objetivos alcançados e foi de extrema importância para a aprendizagem dos alunos da amostra estudada que apresentavam dificuldades de aprendizagem e não realizavam atendimento especializado fora da escola e também para o aperfeiçoamento das práticas da professora pesquisadora regente da turma. A professora, além de enriquecer sua metodologia de trabalho com o auxílio da abordagem interdisciplinar e do uso da ludicidade em 
suas técnicas no contexto da sala de aula, também se aprofundou teoricamente sobre o assunto estudado.

A aplicação de três sequências didáticas em três momentos também foi um grande desafio, sabe-se dos poucos recursos de que os professores dispõem nas escolas e, nesse contexto, não é diferente. Por isso, muito dos materiais utilizados, como jogos, foram construídos com recursos da própria pesquisadora, docente regente da turma estudada. Isso, muitas vezes, é um entrave na mudança de postura dos professores frente a metodologias mais práticas e lúdicas, pois demanda tempo fora do horário de trabalho e recursos financeiros próprios.

O objetivo maior dessa pesquisa era a aprendizagem das crianças, mas, sem dúvida, houve inúmeros outros benefícios. Um deles foi que as crianças adquiriram desejo de ir para escola e frequentar as aulas, pois elas se tornaram mais divertidas e dinâmicas, proporcionando ao mesmo tempo aprendizagem e diversão. A pesquisadora, professora regente da turma, ressaltou que, em quatro anos de trabalho na escola estudada, com certeza, foi a turma mais assídua, pois é característica da comunidade a falta de estímulo para frequentar as aulas.

Sabe-se da importância da frequência escolar para se ter aprendizagem. Um dia de falta na aula se constitui em explicações e atividades perdidas e assim perde- se o "gancho" entre as ações desenvolvidas na escola, o que resulta em prejuízos na aprendizagem. E, para educandos com dificuldades e distúrbios de aprendizagem, ressalta-se que pode ser mais complicado, pois, além de não haver seguimento no acompanhamento dos conteúdos e atividades propostas, na maioria das vezes, acarreta mais desestímulo com os estudos e, posteriormente, evasão escolar, que se caracteriza por ser a saída definitiva do aluno da escola. E, como consequências, são gerados grandes prejuízos para a vida dessas crianças nas diferentes esferas, não só do desenvolvimento cognitivo, que se caracteriza por ser mais um motivo para continuidade da desigualdade social, ou seja, sem estudar, dificilmente conseguirão mudar suas realidades. 
Outro ponto observado que merece destaque é a construção da autonomia e organização da turma. Ao longo do ano, aprenderam a se organizar e interagir com os colegas nas atividades em grupo. No início do ano, os atritos e a dificuldade de formar grupos eram frequentes e intensos.

A aprendizagem que as crianças adquiriram foi importante em todos os âmbitos, mas é relevante ressaltar que nem todos se alfabetizaram, a grande maioria avançou de nível, mas a alfabetização não se concluiu, o que foi considerado muito importante, pois o avanço de nível é fundamental para que ocorra a alfabetização.

Portanto, essa pesquisa trouxe muitos benefícios para todos os envolvidos, professora, alunos e pais, mostrando que métodos interdisciplinares e lúdicos promovem muito além de aprendizagem, promovem a linguagem, o pensamento, a socialização, a iniciativa, a autoestima, entre muitos outros fatores importantes para o desenvolvimento das crianças.

É importante também ressaltar que os métodos interdisciplinares e lúdicos utilizados não garantem aprendizagem, pois ela é um processo, mas eles contribuem muito na sistematização dos conteúdos por meio de metodologias ativas, as quais permitem que os alunos participem de seu processo de aprendizado, tornando as aulas mais dinâmicas e interessantes e, consequentemente, mais proveitosas.

Cabe apontar que a pesquisa revelou que crianças com distúrbios de aprendizagem necessitam não só de técnicas e metodologias de ensino dinâmicas, mas também de tratamento especializado. Para isso, é fundamental que os professores estejam conscientes do seu papel, da sua influência e da importância de se ter uma postura frente ao tema estudado. Para enfrentar essa questão, é fundamental o docente saber/conhecer a temática das dificuldades e dos distúrbios de aprendizagem e isso torna-se possível por meio de leituras, capacitação e formações sobre o assunto.

Ressalta-se que é importante observar que, estando capacitado e atento aos sinais que aparecem na sala de aula e no desempenho do estudante, 0 educador poderá realizar os encaminhamentos necessários para intervir a tempo e contribuir no processo de ensino e aprendizagem. 


\section{Referências}

BRASIL. Lei $n^{\circ}$ 9.394, de 20 de dezembro de 1996. Estabelece as diretrizes e bases da educação nacional. Diário Oficial da União, Brasília, 23 de dezembro de 1996.

BRASIL, Ministério da Educação. Ensino Fundamental de nove anos: orientações para a inclusão da criança de seis anos de idade. Brasília, DF: MEC, 2007. Disponível em: http://tinyurl.com.br/3a0. Acesso em: 10 out. 2018.

FABRICIO, N. M. C. Psicopedagogia: avanços teóricos e práticos. São Paulo: ABPp, 2000.

FAVERO, A.; TONIETO, C.; CONSÁLTER, E. (Orgs.). Interdisciplinaridade e formação docente. 1. ed. Curitiba: CRV, 2018.

FAZENDA, I. C. A. Integração e interdisciplinaridade no ensino brasileiro: efetividade ou ideologia. 6. ed. São Paulo: Edições Loyola, 2011.

FERREIRO, E.; TEBEROSKY, A. Psicogênese da língua escrita. 4. ed. Porto Alegre: Artes Médicas, 1991.

LUCKESI, C. C. Estados de consciência e atividades lúdicas. In: PORTO, Bernadete. Educação e ludicidade. Salvador: UFBA, 2006. p. 11-20. (Ensaios $3)$.

LUCKESI, C. C. Ludicidade e atividades lúdicas: uma abordagem a partir da experiência interna. Ensaios, Salvador, n. 2, p. 22-60, 2004. Disponível em: http://tinyurl.com.br/39z. Acesso em: 24 jul. 2019.

MAYER, J.; SALOVEY, P. What Is Emotional Intelligence? In: SALOVEY, P.; SLUYTER, D. (ed.). Emotional development and emotional intelligence. Educational Implications. New York: Basic Books, 1997. p. 3-31.

OSTI, A. Dificuldades de aprendizagem, afetividade e representações sociais: reflexões para a formação docente. Jundiaí: Paco Editorial, 2012.

PEREIRA, M. LIMA, A.P. PEREIRA, A. A importância da ludicidade na educação infantil para o processo de ensino aprendizagem. Disponível em: https://www.brazilianjournals.com/index.php/BRJD/article/view/18155/14665

Acesso em: 19 de dez de 2020.

PIAGET, J. A representação do mundo na criança. Aparecida: Ideias e Letras, 2005.

PIAGET, J. O juízo moral na criança. 4. ed. São Paulo: Summus, 1994.

SANTOS, C. A. dos. Jogos e atividades lúdicas na alfabetização. Rio de Janeiro: SPRINT, 1998.

TEDESCO, J. C. O novo pacto educativo: educação, competitividade e cidadania na sociedade moderna. São Paulo: Ática, 2002. 
THIOLLENT, M. Metodologia da pesquisa-ação. São Paulo: Cortez. 2011.

VYGOTSKY, L. S. A formação social da mente: o desenvolvimento dos processos psicológicos superiores. 5. ed. São Paulo: Martins Fontes, 1994.

ZORZI, J. L. Os distúrbios de aprendizagem e os distúrbios específicos de leitura e escrita. CEFAC, 2004 . Disponível em: http://www.cefac.br/library/artigos/2405420cdd61d3c9ba0387897e1316ed.pdf. Acesso em: 9 jan. 2020.

\section{Sobre os Autores}

\section{Leticia Gonçalves Borin Moro}

leticiagborin@yahoo.com.br

Possui graduação em Licenciatura em Pedagogia pela Universidade Federal de Santa Maria (2010), especialização em Gestão Educacional EAD pela Universidade Federal de santa Maria (2012). Especialização em Mídias da Educação EAD pela Universidade Federal de Santa Maria (2017). Atualmente atua como professora anos iniciais e educação infantil no município de Santa Maria, RS. Mestre em Ensino de Humanidades e Linguagens, UFN, Santa Maria, RS.

\section{Janaína Pereira Pretto Carlesso}

janapcarlesso@yahoo.com.br

Possui graduação em Psicologia pela UNIFRA atual (UFN); Especialista em Educação Especial: Altas Habilidades/Superdotação pela (UFSM); Mestre em Distúrbios da Comunicação Humana pela (UFSM); Doutora em Educação em Ciências: Química da Vida e Saúde pela (UFSM). Na Universidade Franciscana (UFN) atua como professora adjunta no curso de graduação em Psicologia, na pós-graduação em Neurociência do Desenvolvimento e da Cognição e no Mestrado em Ensino de Humanidades e Linguagens (MEHL). 